\title{
Complementary Medicine and Venous Ulcers: Review of Literature
}

Cioinac SE*

University of Rome Tor Vergata, Hospital Dialysis Centre Bentivoglio AUSL Bologna, Italy

\begin{abstract}
Introduction: Complementary medicine has ancient historical roots and its use is constantly changing. It alongside scientific medicine is useful in the treatment of many diseases, including oncological, respiratory, and dermatological. It is used in the treatment of pain and in the local treatment of various ulcers (lesions) skin. In particular, scientific medicine uses several treatments for venous ulcers with not completely effective outcomes. Effective treatment prevents complications and improves the quality of life of patients. There is scientific evidence on the efficacy of complementary medicine in the treatment of venous ulcers of the lower limbs.
\end{abstract}

Methods: It was performed as a literature review on the databases: MEDLINE, EMBASE and COCHRANE with the aim of detecting the evidence of efficacy of complementary medicine interventions in the treatment of venous ulcers and ways to treat it. We used the keywords and thesaurus descriptors for complementary medicine. We included the following drawings of relevant studies to the subject of the research: systematic reviews randomized controlled trials (RCTs), case control studies, observational studies, case reports, studies, and expert opinion in English, conducted on humans. For the purpose of this research, 174 documents were identified, of which only 15 were relevant and were within the inclusion criteria.

Results: An analysis of the literature shows that many studies have evaluated the effectiveness of aloe, calendula, standardized extract from the aerial parts of $A$. pichinchensis, Mimosa tenuiflora, modified linen bandages, products made of honey found on the market, herbal therapies, polarized light therapy combined with herbal and plant biomembranes. However, these findings are insufficient to support or deny that one treatment is more effective than another. These results are not widely generalizable because of the low number of samples studied.

Conclusion: Despite the interest in complementary medicine and the treatment of venous ulcers, there is currently no truly effective treatment strategy. The detected evidence is insufficient to make significant changes in the treatment of venous leg ulcers with complementary medicine interventions. The available studies on the treatment of venous leg ulcers with products based on plants have not established the existence of a treatment that may be effective individually. Additional studies would be needed to demonstrate the efficacy of these treatments.

Keywords: Complementary medicine; Vascular ulcers; Skin lesions; Lower limbs

\section{Introduction}

Complementary medicine refers to a group of diagnostic and therapeutic disciplines that exist largely outside the institutions in which conventional healthcare is taught and dispensed. In the 70s and 80 s these disciplines were primarily paid in alterative conventional healthcare and thus became known collectively as 'alternative medicine'. The name 'complementary medicine' has developed in the moment in which the two systems have begun to be used from one set to another, up to define the same disciplines group [1-3]

There are more than 300 types of approaches for the complementary medicine applications. A classification drawn up in 1999 by the National Institute of Health (NIH) provides for the following categories: food and nutrition, psycho-therapies (meditation, biofeedback, hypnosis), traditional therapies (Chinese medicine, indigenous healing methods), pharmacological or biological treatment (homeopathy), manual healing (massage, chiropractic, reflexology, reiki, shiatsu, therapeutic touch) and phytotherapy (herbal medicine, aromatherapy) [4]. A quick look at scientific literature allows us to state that complementary medicine is used in different kinds of oncology, respiratory diseases in children, pregnancy, in pain, migraine and in the dressing of various skin lesions [5-12]. Ulcers on the lower limbs require special attention, as they have a significant impact on the patients' quality of life. Additionally, they are difficult and expensive to treat [13-20]. The treatment of this disease is systemic especially through the use of local products that determine the cleansing of the wound and gradual regeneration. Literature demonstrates the use of different dressings in vascular ulcers with more or less positive results [21-27].

In their RCT examine the use of different types of simple dressings in the presence of compression. None of these studies identify any difference in the proportion of patients cured to completion of the study $[27,28]$. Schulze et al. have compared the idropolimeriche dressings with alginates and films or alginates and buffers, all used in the presence of compression in a RCT that included 113 subjects without finding significant differences in the daily ulcer reduction percentage. Complete healing of the ulcer was not an outcome of this study [29]. Argue that the current evidence does not suggest that alginates are effective in the healing of venous leg ulcers compared to hydrocolloid dressings or non-members $[30,31]$. Also, there is no evidence to indicate a difference between the different alginate dressings. However, the RCTs analysed are considered to be of low methodological quality and unclear. They

*Corresponding author: Simona Elena Cioinac, University of Rome Tor Vergata Dialysis Centre Bentivoglio, AUSL Bologna, str. Marconi 45, Hospital, Italy, Tel: 3494370660; E-mail: cioinac.simona@libero.it

Received January 09, 2017; Accepted February 06, 2017; Published February 13, 2017

Citation: Cioinac SE (2017) Complementary Medicine and Venous Ulcers: Review of Literature. Health Care Current Reviews 5: 186. doi: 10.4172/23754273.1000186

Copyright: () 2017 Cioinac SE. This is an open-access article distributed unde the terms of the Creative Commons Attribution License, which permits unrestricted use, distribution, and reproduction in any medium, provided the original author and source are credited. 
conclude by mentioning that RCTs are needed to be well-designed and well-conducted to minimize bias, before drawing firm conclusions regarding the effectiveness of the alginate dressings in the management of venous leg ulcers. The case series of Cioinac shows the positive effect of calendula cream in traumatic lesions on the lower limbs of diabetic patients [32].

The most important aspect of treatment of venous leg ulcers is the application of suitable topical treatments. The dressings should be effective as well as simple, low cost, and acceptable to the patient. In addition to doctors and pharmacists, nurses get the most information on the use of various drugs by patients. The communication between the patient and healthcare professional regarding the use of complementary medicine is crucial to avoid potentially harmful interactions between complementary therapies and conventional therapy [33-44]. The research on complementary medicine is still in the early stages, and recent official reports require an international search for more answers about its effectiveness $[45,46]$. Supervision of the use of techniques and procedures is needed to reduce the problems of efficacy and safety of complementary medicine, avoid potentially harmful interactions between complementary therapies, and conventional therapy [40-44]. Further studies are needed to understand and use this type of medicine [47]. In addition, the medical/ nursing education is critical to convey confidence to patients who wish to use complementary treatments [47-50].

Considering the spread of complementary medicine and its littleknown efficacy, this study aims to conduct a review of international biomedical literature. The review is to collect evidence on the use of complementary medicine in the treatment of venous leg ulcers and the most effective means to treat them, in support of the current practice and to improve the quality of life. The results of this review may help clinicians to identify effective complementary treatments to be used in the treatment of venous leg ulcers.

\section{Materials and Methods}

\section{Research strategy}

A three-phase search strategy was used [51,52]. An initial MEDLINE search using the Mesh terms was undertaken to identify relevant articles. These were used to identify other keywords that were used in a second search of MEDLINE, EMBASE and COCHRANE. Studies which referred only to alternative medicine and studies which were not directly oriented towards the treatment of vascular ulcers have been excluded. In the research, we used the following keywords appropriately combined by Boolean operators or some examples are: 'Complementary'/exp AND 'venous ulcers'/exp * varicose ulcer or stasis venous insufficiency ${ }^{*} \mathrm{OR}$ venous insufficiency varicose ulcer AND complementary medicines 'Complementary medicine'/exp 'Venous ulcers'/exp.

\section{Types of studies and participants}

On the basis of the treatment used, all of the following study designs have been included. These are: systematic reviews, RCTs, case control studies, observational studies, case reports and expert opinions. All studies, abstracts, and full-texts, relevant to the topic of research have been included. There have been no studies that showed the use of Chinese medicine. The target population consisted of adult patients with venous ulcers on the lower limbs undergoing complementary medical treatments. The set limits were: patients over 18 years, studies in humans, and studies published in English. This research was carried out without setting any time limit until the literature published in August 2016.

\section{The quality and diversity of studies}

For the purpose of effectively representing the quality of studies and to adequately reflect on the strength of the evidence an evaluation of the quality of study designs, the optimal conduct of research under consideration taken for each design study was undertaken. Also, the quality of reporting, that is, the completeness of the description of the studies for the purpose of publication was assessed [53-57]. It was evaluated to determine whether the heterogeneity studies were homogeneous, that is sufficiently similar in regard to the treatment used, participants, interventions, control condition, the result and the follow-up time to be combined into a single comparison. In view of the heterogeneity of the treatments used, we assessed the need to regroup the studies according to the treatment used.

\section{Data Analysis}

A qualitative analysis was conducted through the different interventions reported above. Data was extracted for each study: the type of treatment, sampling, settings, time of treatment, the results and measurements. The results were recorded and used to generate brief descriptions. The heterogeneity of the studies in terms of treatment, methods and results has led to several studies adopting a more descriptive approach.

\section{Results}

The literature search produced 174 citations, of which 159 were excluded as being irrelevant. After eliminating duplicates, studies that responded to our research question were selected. So, the research carried out on the three above mentioned databases, after reading the titles and abstracts, led to the selection of 13 studies and two opinions of the experts which will be addressed separately. An analysis of selected studies and different treatments has been identified. The following are the results of the studies found, grouped by specific intervention studied. The references are presented in, indicating for each study, year, author, type of study design, sample, treatment, and main results (Tables 1-3).

\section{Aloe}

In three studies aloe therapy was used for the treatment of venous leg ulcers. Panahi et al. in its RCT on a sample of 60 patients divided in two groups compares Aloe vera with phenytoin cream [58]. The aloe cream resulted in accelerates the healing of chronic wounds and it helped to reduce the intensity of pain with superior efficacy compared to the cream phenytoin. Wound healing it was evaluated using the BatesJensen assessment tool and the severity of pain it was evaluated using a visual analogue scale (VAS). Although aloe it led to healing of venous leg ulcers and decreased pain, the author has included only six patients with venous ulcers. The sample is too small. The study is of poor quality and has a high risk of bias. Dat et al. makes no direct reference to venous ulcers [59]. The Avijgan describes the results of Aloe vera in vascular ulcer treated for 160 days with systemic antibiotics, antiseptic solutions for topical use, surgical debridement and even skin grafting but all with negative results [60]. The results seem good but the study has a low level of evidence because it is presented only one case (Figure 1).

\section{Marigold (Calendula)}

The marigold extract prepared in an apparatus devised by Soxhlet embedded in a neutral base, Duran et al. was administered to a sample of 21 patients (33 venous ulcers) twice a day for three weeks [61]. Calendula would be effective in the experimental group: the total area of 
Citation: Cioinac SE (2017) Complementary Medicine and Venous Ulcers: Review of Literature. Health Care Current Reviews 5: 186. doi: 10.4172/2375-4273.1000186

Page 3 of 7

all ulcers decreased by $41.71 \%$ and in seven patients reached complete re-epithelialization. The second group, the control group consisted of 13 patients ( 22 venous ulcers) and was treated with saline dressings applied on ulcers for three weeks. The results demonstrate that the total area of all the ulcers would decline by $14.52 \%$ and only in four patients reached complete re-epithelialization. Although the results suggest positive effects, the sample size is reduced. In the interventional study only one patient was treated with oral homeopathic therapy and

\begin{tabular}{|c|c|c|c|c|}
\hline Author(s)/year & Study design & Sample & Treatment & Results \\
\hline Panahi et al., 2015 [58] & $\mathrm{RCT}$ & $\begin{array}{l}60 \text { patients divided into } 2 \\
\text { groups ( } 14 \text { with pressure } \\
\text { ulcers, } 6 \text { with venous ulcers, } \\
13 \text { with diabetic lesions) }\end{array}$ & $\begin{array}{l}\text { Application of aloe cream } \\
\text { versus phenytoin as a standard } \\
\text { treatment for a period of } 30 \\
\text { days. }\end{array}$ & $\begin{array}{l}\text { The effectiveness of aloe (intervention group, } p<0.001 \text { ) } \\
\text { and were higher than the fenitonina cream (control group, } \\
p<0.01 \text { ). }\end{array}$ \\
\hline Dat et al., 2012 [59] & Systematic review & $\begin{array}{l}347 \text { patients. They included } \\
\text { seven trials: } 6 \text { trials patients } \\
\text { with acute injuries (emorroi- } \\
\text { dectomia, burns, skin } \\
\text { biopsies) and one trial on } \\
\text { chronic injuries. }\end{array}$ & $\begin{array}{l}\text { Effects of Aloe vera and its } \\
\text { by-products (dressings and } \\
\text { gels) in the treatment of acute } \\
\text { injuries (lacerations, surgical } \\
\text { wounds, burns) and chronic } \\
\text { wounds (wound infections). }\end{array}$ & $\begin{array}{l}\text { Aloe vera has not improved healing compared to } \\
\text { silver sulfadiazine in burns (risk ratio (RR) } 1.41,95 \% \\
\text { confidence interval }(\mathrm{Cl}) 0.70 \text { to } 2.85 \text { ). A reduction } \\
\text { in healing time with } A \text { loe vera was noticed in } \\
\text { haemorrhoidectomy (RR } 16.33 \text { days, } 95 \% \mathrm{Cl} 3.46 \text { to } \\
77.15 \text { ). There was no difference in the percentage of } \\
\text { fully recovered patients at follow-up after skin biopsies. } \\
\text { In people with chronic wounds, one RCT was found, } \\
\text { where Aloe vera (RR } 0.1095 \% \mathrm{Cl}-1.59 \text { to } 1.79 \text { ) does not } \\
\text { present significant data. }\end{array}$ \\
\hline Avijgan, 2004 [60] & Case report & 1 patient & $\begin{array}{l}\text { Application of gel to the Aloe } \\
\text { vera } 2 / 3 \text { times a day. }\end{array}$ & The injury healed completely after 58 days \\
\hline
\end{tabular}

Tabele 1: Evidence table aloe.

\begin{tabular}{|c|c|c|c|c|}
\hline Author(s)/year & Study design & Sample & Treatment & Results \\
\hline Duran et al., 2005 [61] & RCT & $\begin{array}{l}\text { Experimental group of } 21 \\
\text { patients ( } 33 \text { venous ulcers). } \\
13 \text { patients of the control } \\
\text { group ( } 22 \text { venous ulcers). }\end{array}$ & $\begin{array}{l}\text { In the experimental group } \\
\text { based on calendula therapy } \\
\text { it was applied twice a day } \\
\text { for three weeks. The control } \\
\text { group was treated with saline } \\
\text { for three weeks. }\end{array}$ & $\begin{array}{l}\text { Calendula is effective in the experimental group: the } \\
\text { total area of all ulcers decreased by } 41.71 \% \text { and in } \\
\text { seven patients reached complete re-epithelialization. In } \\
\text { the control group, the total area of all was decreased } \\
\text { by } 14.52 \% \text { and in } 4 \text { patients has been reached the } \\
\text { complete re-epithelialization. }\end{array}$ \\
\hline Das, 2013 [62] & Case-control study & 1 patient & $\begin{array}{l}\text { Oral treatment with: Natrum } \\
\text { Mur 200, } 200 \text { Arnica, Ars alb } \\
\text { 30, Ipec } 30, \text { Natrum sulph } \\
\text { 200, Lyco-podium, Calc sulph } \\
\text { 30, Silica 200. Local treatment } \\
\text { with Calendula. }\end{array}$ & $\begin{array}{l}\text { Venous ulcers and limb varicose completely healed after } \\
\text { about five months. }\end{array}$ \\
\hline
\end{tabular}

Tabele 2: Evidence table Calendula oficinalis.

\begin{tabular}{|c|c|c|c|c|}
\hline Author(s)/year & Study design & Sample & Treatment & Results \\
\hline Frade et al., 2012 [63] & Observational & 21 patients & $\begin{array}{l}\text { Application twice a day of plant } \\
\text { biomembranes }\end{array}$ & Healing: 6 weeks. \\
\hline $\begin{array}{l}\text { Romero-Cerecero et al., } 2011 \\
\text { [64] }\end{array}$ & RCT not blind & $\begin{array}{l}\text { Sample of } 34 \text { patients }(50 \% \\
\text { for each group). }\end{array}$ & $\begin{array}{l}\text { Standardized extract from the aerial } \\
\text { parts of } A \text {. pichinchensis in patients with } \\
\text { chronic venous leg ulcers versus the } \\
\text { suministración of propylene glycol alginate. }\end{array}$ & $\begin{array}{l}\text { A. pichinchensis standardized extract } \\
\text { was found to be more effective } \\
(p<0.005) \text {. Only } 7 \% \text { of patients treated } \\
\text { with propylene glycol arginate formula } \\
\text { were healed. }\end{array}$ \\
\hline $\begin{array}{l}\text { Skórkowska-Telichowska et } \\
\text { al., } 2010 \text { [65] }\end{array}$ & $\mathrm{RCT}$ & 30 patients sample. & $\begin{array}{l}\text { The application of a bandage of modified } \\
\text { flax (linseed plant) for } 12 \text { weeks to } \\
\text { evaluate the healing rate, the exudate and } \\
\text { wound size reduction versus placebo was } \\
\text { evaluated. }\end{array}$ & $\begin{array}{l}\text { The healing happened in } 12 \text { weeks and } \\
\text { there was a decrease in pain. }\end{array}$ \\
\hline Binić et al., 2010 [66] & RCT not blind & $\begin{array}{l}17 \text { patients in experimental } \\
\text { group and } 15 \text { patients in } \\
\text { control group. }\end{array}$ & $\begin{array}{l}\text { This work studied the treatment with herbal } \\
\text { therapy versus antibiotic treatment for } \\
\text { venous ulcers in the legs. }\end{array}$ & $\begin{array}{l}\text { In the group of experimental reduction } \\
\text { of ulcers after seven weeks of treatment } \\
(p<0.05) \text { there was a decrease in } \\
\text { isolated bacterial species }(p<0.05) . \\
\text { In the control group, there was no } \\
\text { significant reduction in dell'ulcere. }\end{array}$ \\
\hline Rivera-Arci et al., 2007 [67] & RCT & 40 male and female patients. & $\begin{array}{l}\text { The efficacy of Mimosa tenuiflora versus } \\
\text { placebo. }\end{array}$ & $\begin{array}{l}\text { Reducing the size of ulcers by } 92 \% \\
\text { after eight weeks in the experimental } \\
\text { group. Only one patient healed in the } \\
\text { control group }\end{array}$ \\
\hline Kegels et al., 2011 [68] & $\begin{array}{l}\text { Observational } \\
\text { study }\end{array}$ & $\begin{array}{l}22 \text { patients (six males and } 16 \\
\text { females, with an age average } \\
\text { of } 64 \text { years). }\end{array}$ & $\begin{array}{l}\text { Local treatment with honey-based products } \\
\text { available commercially }\end{array}$ & $\begin{array}{l}\text { Healed lesions after } 12 \text { weeks of } \\
\text { treatment }\end{array}$ \\
\hline Peric et al., 2011 [69] & RCT not blind & 60 patients sample. & $\begin{array}{l}30 \text { patients treated with polarized light and } \\
\text { herbal remedy }\end{array}$ & $\begin{array}{l}\text { Patients were seen at baseline and at } \\
+1,+3,+5 \text { and }+7 \text { weeks of treatment. } \\
\text { Patients healed after seven weeks }\end{array}$ \\
\hline
\end{tabular}

Table 3: Evidence tables other herbal treatments. 


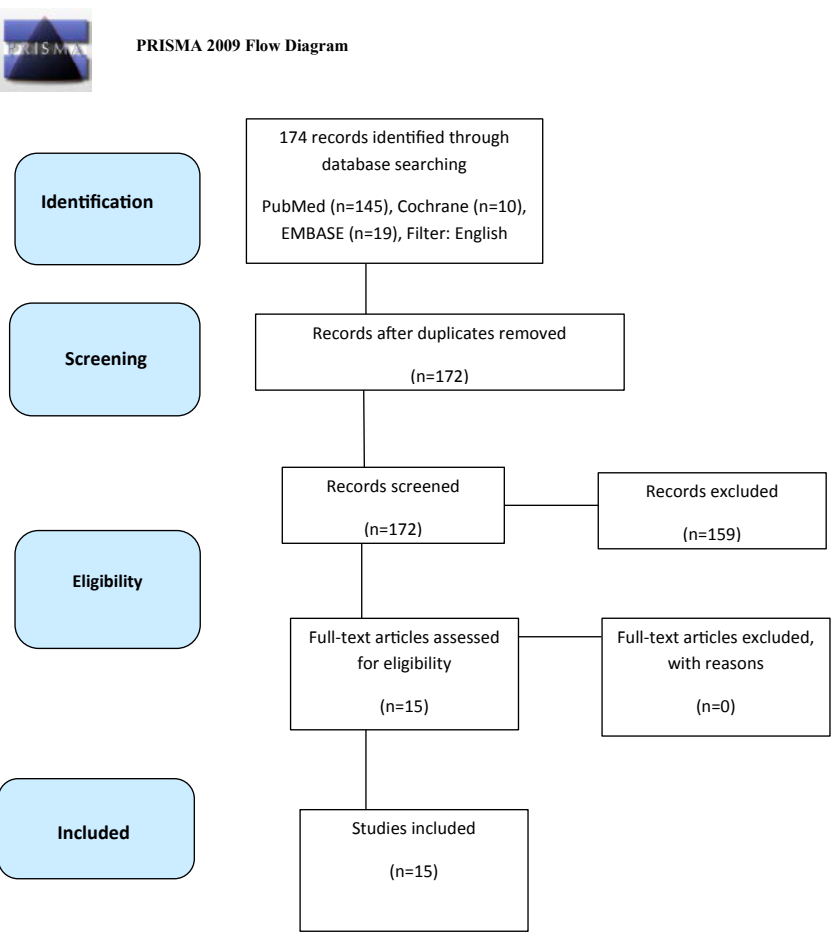

Figure 1: PRISMA 2009 flow diagram [51].

calendula as a local venous ulcer treatment. In a short time, the results were good, but only one case is presented [62].

\section{Plant biomembranes}

Use of plant biomembranes in the treatment of venous ulcers in 21 patients demonstrated good results data from a rich exudation and debridement of the wound, increased tendency to angiogenesis, followed by re-epithelialization [63]. Also in this study the sample is small.

Pichinchensis: Romero-Cerecero et al. as a RCT evaluating the efficacy and tolerability in the topical administration of a processed product with standardized extract from the aerial parts of A [64]. Pichinchensis in patients with chronic venous ulcers of the lower limbs against the administration of propylene glycol alginate. A sample of 34 patients (50\% for each group) were considered. It showed that the standardized extract $A$. pichinchensis is effective in the treatment of chronic venous ulcers in $100 \%$ of the treated patients and, compared with $7 \%$ propylene glycol arginate formula, it achieves a significant reduction of the time required for the healing of ulcers $(\mathrm{p}<0.005)$. Despite the positive effects obtained, the sample size is too small to be able to generalize the results.

\section{Flax blind fold}

Pilot study where modified flax bandage (flax plant) is applied for 12 weeks to a sample of 30 patients to evaluate the healing rate, the exudate, and the size reduction of the wound. It demonstrated the complete wound healing and pain relief [65]. Wound healing is completed during the survey period. Interestingly, and most importantly, patients have reported that the new modified linen bandage decreased the pain that accompanied chronic venous ulcers. This is the first pilot study sheds light on the benefits of linen bandages in the treatment of venous leg ulcers. But, it is just a pilot study and the data cannot be generalized.

\section{Herbal therapies}

Binic et al. presents the data of its pilot study RCT where 17 patients were treated with herbal therapies compared to 15 patients treated with topical antibiotics [66]. The ulcers of venous leg healed after seven weeks of treatment $(\mathrm{p}<0.05)$ and the number of different types of isolated bacterial species decreased. In the control group, the topical antibiotic treatment did not result in any significant reduction dell'ulcere. The results of the pilot study demonstrated that the healing and antibacterial effects of herbal therapy on venous ulcers were not infected. But, the author clearly describes the herbs used. It is, however, just a pilot study and the results cannot be generalized.

\section{Mimosa tenuiflora}

Rivera-Aric et al. in his RCT compares the treatment with Mimosa tenuiflora with placebo. The follow-up lasted 13 weeks and healing venous dell'ulcere was determined by measuring the wound surface by photographic parameters. An analysis of the results showed that after eight weeks the size of the ulcers was reduced by $92 \%$ [67]. Only one patient in the control group demonstrated the therapeutic efficacy. The sample had only 20 patients.

\section{Products made from honey}

The observational study of Kegels was based on a sample of 22 patients presenting data obtained by administering local treatment with products based on honey available commercially [68]. All patients had injuries lasting at least four weeks unhealed. They had mainly been treated with povidone iodine or fusidic acid. About $50 \%$ of the wounds were infected. All wounds were treated with products based on honey and covered with a simple dressing for protection and absorption of exudate. The wounds healed without adverse effects, the level of glucose in the blood remained unchanged, and the dressing changes were painless. The results indicated that products made with honey are antibacterial, help to debride wounds, and promote wound healing. This method is easy to practice and convenient. However, the treated sample is very small.

\section{Polarized light and herbal remedies}

Polarized light and an herbal remedy used by Peric et al. as a RCT of a group of 30 control patients, would give good results. Patients with various venous ulcers on the lower limbs were treated with a combination polarized light and herbal therapy [69]. To study the rate of its influence on wound healing, 3 components of the healing process were studied: A reduction in area, depth, and volume of leg ulcers. Patients were seen at the baseline at $+1,+3,+5$ and +7 weeks of treatment. Comparing the scores, it can be said that the combination of polarized light and herbal remedies accelerated ulcer healing.

Two expert opinions were found that emphasize the importance of complementary medicine in the treatment of venous leg ulcers. Belcaro et al. exposes the effectiveness of TECA in the treatment of various problems of microcirculation, inflammatory skin conditions (leprosy, lupus, venous ulcers, eczema, atopic dermatitis, psoriasis) and also intestinal problems, fever, amenorrhea and genito-urinary conditions [70]. Gotu Kola is widely used mainly as a compound (TECA). Triterpene fraction, the primary constituents of Centella asiatica, produces a wide range of preventive and therapeutic effects. The modulation of collagen production and deposition in the healing of wounds is of primary importance. The article published in 2011 was a result of a meeting of experts held in Cobham, Surrey.

It says that the therapeutic potential of TECA is yet to be explored 
in further studies. The article forms the basis of a consensus document on TECA to be developed in the near future. This document opens a new window on an old product not yet fully studied that may become important in the prevention and treatment of various preclinical conditions and at risk in clinically significant disease as an individual product and in association with other products. Bühring states that physical activity, bandages and oral local therapy, and herbal interventions would be effective peripheral venous insufficiency, in the prevention and treatment of vascular ulcers. Further studies would be needed to prove their efficacy [71].

\section{Discussion}

An examination of the literature shows that studies are few and that various protocols have tried to highlight the effectiveness of treatments, not reaching, however, consistent results. The studies are very heterogeneous and this has made it difficult to compare the results. The differences concern not only the treatment or the sample but also the underlying disease of the patient. It 'was difficult to detect only the studies that have analysed the vascular lesions as many authors have studied the vascular lesions along with other injuries. The RCTs included in one review presents the results of Aloe vera in the treatment of people with chronic wounds, including venous ulcers, and no significant data.

The author places the venous ulcers along with chronic lesions without presenting the results separately. Also, the study is of poor quality and has a high risk of bias. It was not possible to separately analyse the results obtained on venous ulcers and compare them with the available evidence. The results achieved with the use of aloe are conflicting. The authors present their findings observed in patients that could encourage the use of aloe as a topical treatment for venous ulcers. Aloe could be an interesting alternative to other approaches, thanks to its anti-inflammatory, antibacterial and analgesic properties, but these studies use very small samples [72]. Aloe vera is used with good results in dermatology and oncology [7,9].

But, in venous leg ulcers evidence demonstrating satisfactory results is still very poor because of small samples, and further studies are needed to prove its effectiveness. Studies that analyse the use of calendula in the local treatment of venous ulcers are only two. The results would seem to demonstrate the effectiveness of marigold and the reduced time for healing. Literature shows that marigold is used in traumatic injuries, in the treatment of dermatitis in patients undergoing radiotherapy with good results [32-36]. Despite the fact that marigold is a plant with remarkable antibacterial properties, the results of the studies described above would seem satisfactory. But, the samples used are extremely small in order to affirm that calendula is effective [32]. Even the plant biomembrane and A. pichinchensis seem to demonstrate a rich exudation and debridement of the wound. However, even in these two studies, the results are not generalizable. Further studies would be needed to more accurately determine the effectiveness of these two treatments.

The modified linseed bandage ports would seem to reduce the size of the wounds and reduce the exudate leading to healing within a short time. An analysis of the results shows that patients have demonstrated a decrease in pain that accompanied chronic ulcers. Chronic ulcers are accompanied by pain leading to a decrease in patient quality of life [16,22-26]. This would be a very interesting result, but further studies are needed to prove these befits. Herbal therapy would seem to have antibacterial effects in helping the healing of venous leg ulcers. Despite several studies in the literature that state that several herbal extracts have anti-microbial capabilities, antibiotic, antibacterial, and analgesic promoting wound healing, this study presents a very small sample and the author clearly describes that herbs have been used. The study on the effectiveness of Mimosa tenuiflora in the treatment of venous leg ulcers would seem to highlight a significant reduction in the size of ulcers within a short time [55]. Given the sample, we cannot recommend this treatment. Analysing the study products made with honey, the results seem very interesting. The application would seem simple, commercially available, and cheap. They are well proven in international biomedical literature on the antibacterial properties of honey [73]. Honey has been used with good results in the fields of dermatology and oncology [611]. This study is just one observational study with a small sample.

It would require a RCT to demonstrate efficacy in venous leg ulcers. Numerous experts invite researchers to conduct further studies to prove effectiveness in TECA products, bandages, and oral therapies based on plants. Currently, there is no successful intervention in the local treatment of venous ulcers and there is not an effective standard product in the cleansing of ulcers and progressive regeneration. The literature demonstrates the use of different dressings in venous leg ulcers [21-27]. The standard for many years was the bandage even if, recently, new studies have identified innovative strategies for the treatment of venous leg ulcers [73-75]. The authors of a recent systematic review of the literature (53) point out that the bandage even in the prevention and treatment of venous leg ulcers is hardly popular with patients. Also, there is no strong evidence to show its effectiveness. In venous leg ulcers is important an appropriate local treatment [20-22]. In this review, several studies show the use of complementary therapies in the local treatment of venous leg ulcers including Aloe vera, Mimosa tenuiflora, calendula, linen bandages, honey-based products and the results would seem that these lead to healing and re-epithelialization in less time compared to treatment with alginates and hydrocolloids [29-31].

The use of complementary medicine in the local treatment of vascular ulcers would be useful but the scientific community needs experienced studies with a good sample size on the use of the products that best demonstrate good results before recommending it. The treatment of vascular lesions is an integral part of nursing care practice and is even more so for nurses who deal with wound care [27]. With proper application of scientific evidence, venous ulcers can be treated correctly. This prevents complications and improves the quality of life of patients [22-27].

\section{Conclusion}

The articles analysed show that despite the interest of complementary medicine in the treatment of venous ulcers, there is still no truly effective treatment strategy. The available studies on the treatment of venous leg ulcers with products based on plants have not established the existence of a treatment that is individually effective. Vascular lesions have a significant impact on the quality of life of patients for adverse outcomes that may have not treated properly [17-19]. Different therapies seem to prevent or reduce the severity of ulcers, but the strength of the evidence was variable and implications suggest that benefits may be specific to certain types of underlying conditions of the patient and treatment $[53,56]$. Many therapies are not considered because the studies do not meet established standards or because they have not achieved sufficient evidence to support a recommendation. The majority of treatments were carried out on very small samples.

Until now, no single intervention has been convincing or demonstrated convincing results. Over the past two decades, complementary therapies have grown in popularity in Western countries. Interest in complementary therapies can be explained as a 'new consciousness' [34]. There are many advantages in complementary 
therapies that are playing a role in the therapeutic care of health of individuals and, through the use of such therapies; nursing is developing new skills [34-36]. However, there are still barriers to overcome; namely, the reluctance to accept complementary therapies in many contemporary healthcare environments. By researching these, barriers can be overcome. The retrieved literature, relevant to our research question, for different therapies in the local treatment of venous ulcers, is quite poor. Our indications of good practice, therefore, derive substantially from a careful examination of all the studies found.

\section{References}

1. D'Innocenzo M (2014) Coaching leadership: Leaders' and followers' perception assessment questionnaires in nursing. Einstein (Sao Paulo) 12:66-74

2. Defining and describing complementary and alternative medicine (1995) Panel on definition and description, CAM Research Methodology Conference. Altern Ther Health Med 3: 49-57.

3. Zollman C, Vickers A (1999) ABC of complementary medicine: Complementary medicine and the doctor. BMJ 319: 1558-1561.

4. Wieland LS, Manheimer E, Berman BM (2011) Development and classification of an operational definition of complementary and alternative medicine for the Cochrane collaboration. Altern Ther Health Med 17: 50-59.

5. Pikó B (2015) Scientific and complementary medicine. Irreconcilable differences or mutually supportive systems. Lege Artis Med 25: 381-386.

6. AlBedah AM, Khalil MK (2015) Cancer patients, complementary medicine and unmet needs in Saudi Arabia. Asian Pac J Cancer Prev 16: 6799.

7. Ben-Arye E, Schiff E, Mutafoglu K, Omran S, Hajjar R, et al. (2015) Integration of complementary medicine in supportive cancer care: Survey of health-care providers' perspectives from 16 countries in the Middle East. Support Care Cancer 23: 2605-2612.

8. Hocaoglu Babayigit A (2015) High usage of complementary and alternative medicine among Turkish asthmatic children. Iran J Allergy Asthma Immuno 14: $410-415$

9. Matthews A, Haas DM, O'Mathúna DP, Dowswell T (2015) Interventions for nausea and vomiting in early pregnancy. Cochrane Database Syst Rev 8: 9.

10. Simpson CA (2015) Complementary medicine in chronic pain treatment. Phys Med Rehabil Clin N Am 26: 321-347.

11. Zheng H, Chen M, Huang D, Li J, Chen Q, et al. (2015) Interventions for migraine prophylaxis: Protocol of an umbrella systematic review and network meta-analysis. BMJ Open 5: e007594

12. Hashemi SA, Madani SA, Abediankenari S (2015) The review on properties of Aloe vera in healing of cutaneous wounds. Biomed Res.

13. Chase SK, Melloni M, Savage A (1997) A forever healing: The lived experience of venous ulcer disease. J Vasc Nurs 15: 73-78.

14. Cullum N, Roe B (1995) Leg ulcers nursing management-a research-based guide. London: Bailliere Tindall.

15. Douglas $V$ (2001) Living with a chronic leg ulcer: An insight into patients experiences and feelings. J Wound Care 10: 355-360.

16. Flett R, Harcourt B, Alpass F (1994) Psychosocial aspects of chronic lower leg ulceration in the elderly. West J Nurs Res 16: 183-192.

17. Franks PJ, Oldroyd MI, Dickson D, Sharp EJ, Moffatt CJ (1995) Risk factors for leg ulcer recurrence: A randomized trial of two types of compression stocking. Age Ageing 24: 490-494.

18. Nelzen O, Bergquist D, Lindhagen, A (1996) The prevalence of chronic lowerlimb ulceration has been underestimated: Results of a validated population study. Br J Surg 83: 255-258.

19. International Working Group on the Diabetic Foot (2015) Prevention and management of foot problems in diabetes: A summary guidance for daily practice based of the IWGDF guidance documents.

20. Lipsky BA, Berendt AR, Cornia PB, Pile JC, Peters EJ, et al. (2012) Infectious Diseases Society of America. Infectious Disease Society of America clinical practical guideline for the diagnosis and treatment of diabetic foot infections. Clin Infect Dis 54: 132-173.
21. Rich A, McLachlan L (2003) How living with a leg ulcer affects people's daily life: A nurse-led study. J Wound Care 12: 51-54.

22. Hareendran A, Bradbury A, Budd J, Geroulakos G, Hobbs R, et al. (2005) Measuring the impact of venous leg ulcers on quality of life. J Wound Care 14: 53-57.

23. Hopkins A (2004) Disrupted lives: Investigating coping strategies for nonhealing leg ulcers. Br J Nurs 13: 556-563.

24. Jull A, Walker N, Hackett M, Jones M, Rodgers A, et al. (2004) Leg ulceration and perceived health: A population based case-control study. Age Ageing 33 236-241.

25. Phillips T, Stanton B, Provan A, Lew R (1994) A study in the impact of leg ulcers on the quality of life: Financial, social and psychological implications. $J$ Am Acad Dermatol 31: 49-53.

26. Price P, Harding K (1996) Measuring health-related quality of life in patients with chronic leg ulcers. Wounds 8: 91-94.

27. Vin F, Teot L, Meaume S (2002) The healing properties of Promogran in venous leg ulcers. J Wound Care 11: 335-341.

28. Andersen KE, Franken CPM, Gad P (2002) A randomized, controlled study to compare the effectiveness of two foam dressings in the management of lower leg ulcers. Ostomy Wound Management 48: 34-36.

29. Schulze HJ, Lane C, Charles H, Ballard K, Hampton S, et al. (2001) Evaluating a superabsorbent hydropolymer dressing for exuding venous leg ulcers. Wound Care 10: 511-518.

30. O'Meara S, Martyn-St James M (2013) Foam dressings for venous leg ulcers Cochrane Database Syst Rev CD009907.

31. van der Riet $P$ (2011) Complementary therapies in health care. Nurs Health Sci 13: 4-8.

32. Cioinac SE (2016) Use of calendula cream balm to medicate the feet of diabetic patients: Case series. Int J Nurs Sci 3: 102-112.

33. Sohn PM, Loveland Cook CA (2002) Nurse practitioner knowledge of complementary alternative health care: Foundation for practice. J Adv Nurs 39 9-16.

34. Hayes KM, Alexander IM (2000) Alternative therapies and nurse practitioners: Knowledge, professional experience, and personal use. Holist Nurs Pract 14 49-58.

35. Tascilar M, de Jong FA, Verweij J, Mathijssen RH (2006) Complementary and alternative medicine during cancer treatment: Beyond innocence. Oncologist 11: 732-741.

36. Dy GK, Bekele L, Hanson LJ, Furth A, Mandrekar S, et al. (2004) Complementary and alternative medicine use by patients enrolled onto phase I clinical trials. J Clin Oncol 22: 4810-4815.

37. Verhoef MJ, Balneaves LG, Boon HS, Vroegindewey A (2005) Reasons for and characteristics associated with complementary and alternative medicine use among adult cancer patients: A systematic review. Integr Cancer Ther 4: 274-286.

38. Shumay DM, Maskarinec G, Gotay CC, Heiby EM, Kakai H (2002) Determinants of the degree of complementary and alternative medicine use among patients with cancer. J Altern Complement Med 8: 661-671.

39. Sparreboom A, Cox MC, Acharya MR, Figg WD (2004) Herbal remedies in the United States: Potential adverse interactions with anticancer agents. J Clin Oncol 22: 2489-2503.

40. Angell M, Kassirer JP (1998) Alternative medicine-the risks of untested and unregulated remedies. N Engl J Med 339: 839-841.

41. Markman M (2002) Safety issues in using complementary and alternative medicine. J Clin Oncol 20: 39S-41S.

42. McCune JS, Hatfield AJ, Blackburn AA, Leith PO, Livingston RB, et al. (2004) Potential of chemotherapy-herb interactions in adult cancer patients. Support Care Cancer 12: 454-462.

43. Parker PA, Urbauer D, Fisch MJ, Fellman B, Hough $\mathrm{H}$, et al. (2013) A multisite, community oncology-based randomized trial of a brief educational intervention to increase communication regarding complementary and alternative medicine. Cancer 119: 3514-3522.

44. Rojas-Cooley MT, Grant M (2009) Complementary and alternative medicine: Oncology nurses' knowledge and attitudes. Oncol Nurs Forum 36: 217-224. 
Citation: Cioinac SE (2017) Complementary Medicine and Venous Ulcers: Review of Literature. Health Care Current Reviews 5: 186. doi: $10.4172 / 2375-4273.1000186$

45. Helms JE (2006) Complementary and alternative therapies: A new frontier for nursing education? J Nurs Educ 45: 117-123

46. Franco JA, Pecci C (2003) Physician-patient relationship, scientific medicine and alternative therapies. Medicina 63: 111-118.

47. Martin JB (2001) Historical and professional perspectives of complementary and alternative medicine with a particular emphasis on rediscovering and embracing complementary and alternative medicine in contemporary Western society. J Altern Complement Med 7 1: S11-8.

48. Reilly D (2001) Comments on complementary and alternative medicine in Europe. J Altern Complement Med 7: S23-S31.

49. Oumeish OY (1998) The philosophical, cultural and historical aspects of complementary, alternative, unconventional and integrative medicine in the old world. Arch Dermatol. 134:1373-1386.

50. O'Meara S, Martyn-St James M, Adderley UJ (2015) Alginate dressings for venous leg ulcers. Cochrane Database Syst Rev CD010182.

51. Moher D, Liberati A, Tetzlaff J, Altman DG (2009) Preferred reporting items for systematic reviews and meta-analyses: The PRISMA statement. PLoS Med 6: e1000097.

52. The joanna briggs institute (2014) Joanna briggs institute reviewers' manual. The Joanna Briggs Institute.

53. Shea BJ, Grimshaw JM, Wells GA, Boers M, Andersson N, et al. (2007) Development of AMSTAR: A measurement tool to assess the methodological quality of systematic reviews. BMC Med Res Methodol 7: 10.

54. Jadad AR, Moore RA, Carroll D, Jenkinson C, Reynolds DJ, et al. (1996) Assessing the quality of reports of randomized clinical trials: Is blinding necessary? Controlled Clinical Trials 17:1-12.

55. Wells G A, Shea B, O'Connel D (2009) The Newcastle-Ottawa scale (NOS) for assessing the quality of non-randomised studies in meta-analyses.

56. http://www.consort-statement.org

57. http://strobe-statement.org/index.php?

58. Panahi Y, Izadi M, Sayyadi N, Rezaee R, Beiraghdar F, et al. (2015) Comparative trial of Aloe vera/olive oil combination cream versus phenytoin cream in the treatment of chronic wounds. J Wound Care. 24: 459-560: 462-465.

59. Dat AD, Poon F, Pham KB, Doust J (2012) Aloe vera for treating acute and chronic wounds. Cochrane Database Syst Rev 2: CD008762.

60. Avijgan M (2004) Phytotherapy: An alternative treatment for non-healing ulcers. J Wound Care 13: 157-158.

61. Duran V, Matic M, Jovanovć M, Mimica N, Gajinov Z, et al. (2005) Results of the clinical examination of an ointment with marigold (Calendula officinalis) extract in the treatment of venous leg ulcers. Int J Tissue React 27: 101-106.
62. Das C (2013) Evidence based homoepaphy in treating long standing and recurring venous ulcer - a prospective and interventional study. Int J Pharm Sci Res 4: 3266-3269.

63. Frade MA, Assis RV, Coutinho Netto J, Andrade TA, Foss NT (2012) The vegetal biomembrane in the healing of chronic venous ulcers. An Bras Dermatolan 87 $45-51$

64. Romero-Cerecero O, Zamilpa-Álvarez A, Jiménez-Ferrer E, Tortoriello J (2012) Exploratory study on the effectiveness of a standardized extract from Ageratina pichinchensis in patients with chronic venous leg ulcers. Planta Med 78: 304 310

65. Skórkowska-Telichowska K, Zuk M, Kulma A, Bugajska-Prusak A, Ratajczak K, et al. (2010) New dressing materials derived from transgenic flax products to treat long-standing venous ulcers-a pilot study. Wound Repair Regen 18:168179

66. Binić I, Janković A, Janković D, Janković I, Vrucinić Z (2010) Evaluation of healing and antimicrobiological effects of herbal therapy on venous leg ulcer: Pilot study. Phytother Res 24:277-282.

67. Rivera-Arce E, Chávez-Soto MA, Herrera-Arellano A, Arzate S, Agüero J, et al. (2007) Therapeutic effectiveness of a Mimosa tenuiflora cortex extract in venous leg ulceration treatment. J Ethnopharmacol 109: 523-528.

68. Filip Kegels (2011) Clinical evaluation of honey-based products for lower extremity wounds in a home care setting. Wounds UK 7.

69. Peric S, Jankovic A, Binic I (2007) Polarised light and herbal remedies: A new formula for venous ulcer healing. Medicus 8: 28-31.

70. Belcaro G, Maquart FX, Scoccianti M, Dugall M, Hosoi M, et al. (2011) TECA titrated extract of Centella asiatica: New microcirculatory, biomolecular and vascular application in preventive and clinical medicine. A status paper. Panminerva Med 53: 105-118.

71. Bühring U (2005) Medicinal plants for the treatment of leg ulcers. Zeitschrift fur Phytotherapie 4: 185-187.

72. Mauck KF, Asi N, Elraiyah TA, Undavalli C, Nabhan M, et al. (2014) Comparative systematic review and meta-analysis of compression modalities for the promotion of venous ulcer healing and reducing ulcer recurrence. J Vasc Surg 60: 71S-90S.e1-2.

73. Song XF, Chen XD (2016) Advances in the research of promotion effect of $A$ loe vera on wound healing and its clinical use. Zhonghua Shao Shang Za Zhi 32: 634-637.

74. Bedi MK, Shenefelt PD (2002) Herbal therapy in dermatology. Arch Dermato 138: 232-242.

75. Roshan N, Rippers T, Locher C, Hammer KA (2016) Antibacterial activity and chemical characteristics of several Western Australian honeys compared to manuka honey and pasture honey. Arch Microbiol. 